\title{
HOW TO MEASURE PROGRESS TOWARDS QUALITY AND SUSTAINABILITY OF LIFE?
}

\author{
PAVEL NOVÁČEK ${ }^{1}$, PETER MEDERLY²
}

${ }^{1}$ Department of Development Studies, Faculty of Science, Palacky University, 17. listopadu 12, 77146 Olomouc, Czech Republic; e-mail: pavel.novacek@upol.cz

${ }^{2}$ Constantine the Philosopher University, Faculty of Natural Sciences, Andreja Hlinku 1, 94974 Nitra, Slovak Republic; e-mail: pmederly@ukf.sk

\begin{abstract}
Nováček P., Mederly P.: How to measure progress towards quality and sustainability of life? Ekológia (Bratislava), Vol. 34, No. 1, p. 7-18, 2015.

The vagueness of the concept of 'sustainable development' ceased to serve as a consensus platform and instead became a source of controversy. Therefore an instrument is needed to measure whether we are striving towards sustainable development or not. Today the most widely used indicator of economic prosperity is gross domestic product (GDP). It is often incorrectly interpreted as an indicator of quality of life. If, however, GDP is considered to be quality-of-life indicator, it is a misleading indicator as GDP does not cover the services people conduct outside the official market. As a result, environmentalists together with economists have long been cooperating in designing an alternative indicator capable of better capturing the development of society. Even though GDP is good for measuring economic performance, it is highly misleading as an indicator of the quality and sustainability of life. This article describes briefly the most relevant alternative indicators to GDP developed during last two decades including Czech and Slovak methodology of the Quality and Sustainability of Life Index.
\end{abstract}

Key words: indicators, alternatives to GDP, sustainability, quality of life.

\section{Introduction}

Reports to the Club of Rome and some other globally oriented reports of the 1970s and early 1980s demonstrated that the exponential growth in production and consumption within the restricted Earth ecosystem is not sustainable in the long term. Therefore in 1983 the UN Secretary-General Javier Perez de Cuellar invited the Prime Minister of Norway, Gro Harlem Brundtland, to establish an international commission that would propose how to enable people and whole nations to develop while sustaining functioning of ecosystems and a healthy environment. The efforts of the World Commission on Environment and Development over the course of 4 years resulted in a report called 'Our Common Future', published in 1987. The key term of, probably the most important, UN report of the 1980s was 'sustainable development'.

According to the UN World Commission on Environment and Development, sustainable development is 'development that meets the needs of the present without compromising the ability of future generations to meet their own needs. In its broadest sense, the strategy 
for sustainable development aims to promote harmony among human beings and between humanity and nature'.

The above definition is so 'all embracing' that it is impossible not to agree with. Its biggest deficiency is the fact that it fails to attempt to even define human needs. Herman Daly (1996) pointed out that in the second half of the 1990s the vagueness of the concept of 'sustainable development' ceased to serve as a consensus platform and instead became a source of controversy. No unified generally accepted definition has been provided yet.

\section{Problem description - how to measure sustainability?}

We must do our best to prevent sustainable development from being just a vague and 'all embracing' concept. Therefore an instrument is needed to measure whether we are striving towards sustainable development or not, and whether the situation is improving or deteriorating.

Today the most widely used indicator of economic prosperity is gross domestic product (GDP). It is often incorrectly interpreted as an indicator of quality of life (the higher the GDP, the higher the quality of life).

GDP is the total monetary value of goods and services generated within a particular period (usually 1 year) in a particular country ${ }^{1}$. GDP is the indicator of the state's economic performance.

If, however, GDP is considered to be the main indicator of prosperity, advance and quality of life, it is a misleading indicator, as GDP does not cover the services people conduct outside the official market (e.g. housework) and neither does it include illegal production (e.g. unreported earnings, the gray economy, prostitution, organised crime). What is even more serious is that GDP does not cover environmental damage or long-lasting damage caused by the use of non-renewable resources. When, for instance, we burn lignite, that produces sulfur oxide and causes adverse impact on the population's health, it does not appear negatively in GDP calculation. On the contrary, when we are forced to spend more money on treatment as a consequence of deteriorated health, it is reflected in GDP positively as growth.

\section{Results - alternatives to GDP}

Many economists have long been cooperating with experts from other areas in designing an alternative indicator capable of better capturing the development of society and not just economic performance in the narrow sense.

\section{Index of Sustainable Economic Welfare (ISEW)}

One of the best attempts at drafting an alternative GDP indicator is the work of the former World Bank economist, Herman Daly, and the theologian, John Cobb, who in 1989 published an Index of Sustainable Economic Welfare (Daly, Cobb, 1989).

\footnotetext{
${ }^{1}$ GDP is composed of consumption (private and governmental), investments and net export (i.e. the difference between exports and imports). Gross national product (GNP) is a similar indicator, measuring the value of goods and services produced by the residents of a country, whether physically located domestically or abroad. Therefore, GNP consists of GDP minus the income of foreigners (e.g. export of foreign investors' gains) plus the income of the residents of a country living abroad.
} 
The Index of Sustainable Economic Welfare is an aggregated indicator based on personal consumption adapted with respect to factors related to social welfare and the quality of the environment.

The ISEW methodology aimed at evaluating the relative performance of the economy in time by taking quality of life into consideration. Similarly to GDP, the index is based on measuring personal consumption in the economy. There are, nevertheless, a number of differences from the conventional measuring method, for instance:

- $\quad$ estimates of the long-term consequences of a damaged environment are included;

- changes in income distribution (reflecting the fact that a dollar in the pocket means more to the poor than to the rich) are included;

- the value of housework is also included so that these non-monetary gains are reflected in the economy.

The long-term costs of environmental damage are composed mainly of:

- cost of air, water and noise pollution;

- cost of lost farmland;

- cost of lost wetlands;

- cost of ozone depletion;

- drawing of non-renewable resources.

The results clearly show that GDP growth in the United States and United Kingdom does not correspond with a growth in the standard of living or the quality of life. This is caused by 'externalities', above all by growing environmental and social costs, including the growing impact of exhausted resources and long-term environmental damage.

Today, more than 20 years later, we can say that ISEW as an alternative indicator of GDP failed to win recognition, even though methodologically it was of great benefit. This might have been due to the complexity of its calculation or to the conservative attitude of economists, who form the mainstream of economic thinking.

\section{Human Development Index (HDI)}

Another indicator has become successful, being regularly evaluated and published by the United Nations Development Programme (UNDP) since 1990. Its strength most likely lies in its simplicity. It is the Human Development Index. UNDP proceeded from the conviction that for a high quality of life at all levels, the following are of utmost importance:

- chance for a long and healthy life;

- $\quad$ access to knowledge;

- $\quad$ access to resources necessary for a dignified life.

Therefore, GDP is based on four indicators reflecting the rate of satisfaction of the elementary human needs:

- life expectancy ${ }^{2}$;

- $\quad \mathrm{GDP}$ at purchasing power parity $(\mathrm{PPP})^{3}$;

${ }^{2}$ Life expectancy at birth, or longevity, expresses the age a newborn baby would live to if the prevalent mortality rate remained the same for the entire duration of its life.

${ }^{3} \mathrm{GDP}$ at PPP takes into account different price levels in different countries. 
- $\quad$ literacy ${ }^{4}$

- gross enrollment ratio ${ }^{5}$.

Education is expressed by two indicators out of four, which emphasises the importance of this indicator.

Comparison of countries by GDP and HDI offers interesting interpretations. For instance, even today former socialist countries reach a higher rank based on HDI than on GDP thanks to their emphasis on literacy, education and basic medical care available to all. Of non-socialist countries, Costa Rica achieves a significantly higher HDI than GDP.

On the other hand, countries exporting oil, the Near East in particular, have significantly lower HDI values than GDP. Their unfavorable HDI is probably caused by the unequal position of women, which is manifested in lower literacy and big social differences (a highly uneven distribution of wealth).

\section{Dashboard of Sustainability}

First developed by the UN Commission on Sustainable Development between 2000 and 2001, the Dashboard of Sustainability is composed of four main areas - environmental, social, economic and institutional. The resulting index was calculated from 45 indicators and is expressed graphically as a 'vehicle's instrument panel', with green representing a satisfactory situation, orange a warning and red a critical situation. It can be used to compare countries and monitor relations between individual indicators. The dashboard of sustainability was assessed for 183 countries of the world. In 2006 version the top five were Sweden, Denmark, Finland, Norway and Iceland, and the bottom five are Afghanistan, Somalia, Niger, Sierra Leone and the Central African Republic

\section{Environmental Sustainability Index (ESI)}

The index was developed at Yale University (Center for Environmental Law and Policy) and Columbia University (Center for International Earth Science Information Network). It centers on the environmental pillar of sustainable development and consists of 5 themes, 21 subthemes and 76 indicators. The five themes are: the situation of the environment and its load, human dependency on and sensitivity to external influences, social capacity, institutional capacity and participation in international cooperation.

The countries with the best scores are Finland, Norway, Uruguay, Sweden and Iceland. The lowest ranking countries are North Korea, Taiwan, Turkmenistan, Iraq and Uzbekistan.

\section{Environmental Vulnerability Index (EVI)}

The Environmental Vulnerability Index was devised jointly by the South Pacific Applied Geoscience Commission (SOPAC) and the United Nations Environment Program (UNEP). The

\footnotetext{
${ }^{4}$ The literacy rate of a population indicates the percentage of people over the age of 15 who can read with understanding and write a simple statement related to everyday life.

${ }^{5}$ The gross enrollment rate is a combined recalculation of enrollment at primary, secondary and tertiary schools.
} 
environment forms the basis not only for the welfare but for the very existence of the people on this planet. The index is intended to complement the existing evaluation of economic and social vulnerability.

Development is always a compromise between the three sustainability pillars - economic, social and environmental. For this reason it is important to know how vulnerable the components of these pillars are. Based on this information, measures for increasing the resistance of endangered components may be proposed. In the case of environmental vulnerability it involves mainly an increase in the ecosystems' resistance. The ecosystems' integrity may be threatened by both anthropocentric and natural hazards.

The main themes of the Environmental Vulnerability Index are as follows:

- climate change;

- biodiversity;

- water;

- $\quad$ agriculture and fisheries;

- human health aspects;

- desertification;

- $\quad$ exposure to natural disasters.

\section{Wellbeing of Nations}

The 'wellbeing of nations' assessment method was developed by the International Union for Conservation of Nature (IUCN). The Wellbeing Index (WI) is assessed based on two main components - the Human Wellbeing Index (HWI) and the Ecosystem Wellbeing Index (EWI). The ratio of human wellbeing and the stress of ecosystems are also expressed by the Wellbeing/Stress Index (WSI). These four indexes combined illustrate the sustainability of development from the local community level up to the global level. The human and ecosystem wellbeing are jointly and equally expressed by the Barometer of Sustainability, which was calculated for 180 countries.

On the basis of this approach, sustainable development is possible only when both the components (the Human Wellbeing Index and the Ecosystem Wellbeing Index) are well. A total of 180 countries of the world were evaluated. The best scores were Sweden, Finland, Norway, Iceland and Austria. The lowest were Iraq, Syria, Afghanistan, Uganda and Saudi Arabia.

\section{Living Planet Index (LPI)}

The Living Planet Index monitors trends related to biological diversity on Earth. THe World Wide Fund for Nature (WWF) monitors a total of 1,313 vertebrate species (fish, amphibians, reptiles, birds and mammals) around the world, which it divides into terrestrial, marine and freshwater animals. The resulting average of these three groups forms an aggregated index.

Although the vertebrates form only a part of the known animal species, it is estimated that the trends are a true reflection of the overall development of biodiversity on Earth and thus also of the quality of ecosystems. 
Since 1970 the index has dropped by $30 \%$, which means that the current rate at which we are destroying natural ecosystems has no parallel in human history.

In terrestrial ecosystems the populations of 695 representative species are monitored. Between 1970 and 2003 the populations dropped by 31\%, mainly due to agriculture.

In marine ecosystems the populations of 274 marine species in four oceans are monitored. Between 1970 and 2003 the index fell by $27 \%$. The mangrove ecosystems (where up to $85 \%$ of commercially fished species are born) are of utmost importance for biological diversity. Between 1990 and 2000 over 25\% of mangrove growth was destroyed in Asia and nearly $50 \%$ in South America.

In freshwater ecosystems the populations of 344 freshwater species (287 species in the temperate zone and 51 in the tropics) are monitored. Between 1970 and 2003 the index fell by $28 \%$. The principal causes behind the decrease are the destruction of the environment in which the species live, excessive fishing, the negative impact of invasive species and the contamination and disruption of the natural water courses.

\section{Ecological Footprint}

The ecological footprint expresses the consumption of natural resources by 'global hectares per capita, which are a comparative unit of the consumption of natural resources and the actual capacity of biologically productive areas on Earth $^{6}$ (Rees, 1992). The ecological footprint has one enormous advantage - it can be assessed at the global, national, local and even at the individual level. The overall ecological footprint of the global population is 3.1 global hectares per capita but the overall ecological capacity is only 2.1 global hectares (data as of 2010). The activities of the human community thus exceed the global ecological capacity by 1 global hectare per capita. ${ }^{7}$ Similarly, more or less all European countries (with the exception of Finland) record an ecological deficit. Viewed from the perspective of the ecological footprint, although the situation is satisfactory in most developing countries, with advancing industrialisation the indicator will likely deteriorate here, too. If the current trends continue, by the 2030 s we will be exceeding the Earth's ecological capacity by $100 \% 8$.

\section{Happy Planet Index (HPI)}

The Happy Planet Index shows the average number of years of a happy life produced (provided) by a given society, state or group of states per unit of consumed natural resources. It

\footnotetext{
${ }^{6}$ The majority of the resources we consume and the waste we produce can be recalculated in area. A total of all areas, generated by the human consumption of resources and the production of waste, creates an 'ecological footprint'. If the area corresponding to the ecological footprint of society exceeds the ecological footprint of a country, the productive area is actually used by people from other countries or at the expense of future generations. Mathis Wackernagel, one of the creators of the 'ecological footprint' concept, notes: 'It is similar to a mortgage, can mortgage the future. We must always bear in mind, though, that we will have to pay the loan back, with interest'. (Personal Communication, 2003).

${ }^{7}$ The first time we exceeded the Earth's ecological capacity was in the 1980s and since then the situation has been worsening. At present we are $50 \%$ beyond the ecological capacity.

${ }^{8}$ We would need two planet Earths to be able to live sustainably. As we do not have them, we will impose a drastic burden on future generations.
} 
describes the efficiency with which countries transform the exhaustible resources of Earth to the welfare (or rather the long and happy life) of their inhabitants. The HPI consists of three indicators: the ecological footprint, life satisfaction and life expectancy.

The Index was devised by the New Economics Foundation in London. Its index does not inform us which country is 'the happiest' in the world. The HPI shows that high levels of resource consumption do not necessarily mean high levels of well-being (a long and happy life). Furthermore, the index reveals there are different routes to achieving satisfactory wellbeing values. The model pursued by Western countries provides a long life with variable life satisfaction, but it does so only at the expense of the excessive and ultimately counterproductive consumption of natural resources. The results show we are still far from achieving sustainable well-being (a long, meaningful life respecting environmental limits).

According to the HPI published in July 2009, Costa Rica scored the highest while Zimbabwe scored the lowest. Of regions, Latin America tops the Index. Based on HPI, 9 out of the top 10 nations are in Latin America. In general, we could say that middle-income countries such as those in Latin America, as well as some countries of South East Asia, tend to reach the highest values of sustainable well-being expressed by the HPI. Of European countries, Iceland ranks the best, followed by Sweden and Norway. Of 30 European countries, postcommunist countries score the worst.

\section{Gross National Happiness (GNH)}

Gross National Happiness is an attempt at defining quality of life in more holistic terms and with greater respect to the non-material aspects of life than GDP. The concept was first introduced in 1972 by Bhutan's King Jigme Singye Wangchuck, who opened Bhutan to modernisation.

None the less, since the beginning the concept has suffered from one deficiency - the definition of happiness is very difficult because it is a highly subjectively experienced condition.

Conventional development methods consider economic growth the most important goal'. The GNH concept is based on the assumption that human society can develop when material and spiritual development go hand in hand, complementing one another. The four pillars of GNH are: the promotion of sustainable development, the preservation and promotion of cultural values, the conservation of the environment and the establishment of good governance.

The critics of the concept of gross national happiness observe it is a series of subjective evaluations concerning the well-being (or rather quality of life) of the population, a fact that a government can take advantage of, adjusting and interpreting the definition of 'national happiness' at its convenience.

GNH is undoubtedly an interesting concept, radically different from GDP. That is why it could be, at least from time to time, also evaluated in countries of other civilisations. The re-

\footnotetext{
${ }^{9}$ Modern classical economists no longer attempt to quantify happiness or satisfaction by measuring consumption or profit. Instead, the Neo-Classical framework argues that individual preferences manifest themselves through choice. If an individual decides to purchase an apple over an orange, the satisfaction (happiness) of an apple is revealed to surpass that of an orange. Similarly modern economists declare that the work/leisure balance is also a matter of individual choice.
} 
sults and their interpretations would definitely start an interesting discussion among experts and probably also in the media.

\section{Genuine Progress Indicator (GPI)}

The Genuine Progress Indicator (GPI) is a concept of 'green economy' (or rather environmental economy) devised to replace GDP, which quantifies economic growth (Daly, 1996)

GPI attempts to measure whether the increased production of goods and services of a country have actually fostered an improvement in the welfare (or rather quality of life) of the inhabitants. GPI should be more reliable in measuring economic progress as it differentiates between useful (meaningful) growth and uneconomic growth ${ }^{10}$.

The difference between GDP and GPI is parallel to the difference between a company's gross profit and net profit. Net profit is gross profit minus the costs incurred.By analogy, GPI is zero if the financial costs of crime rates and a polluted environment equal the financial gains of the production of goods and services (provided the other factors are considered constant).

The 'costs' of economic activities include, above all, the following harmful effects:

- $\quad$ cost of resource depletion;

- cost of crime;

- cost of ozone depletion;

- cost of family breakdown;

- cost of air, water, and noise pollution;

- cost of farmland loss;

- cost of wetland loss.

We often devastate nature's capacity to perform for us a number of ecosystem services such as the natural clearing of waste, the limitation of erosion, etc. in the name of monetary gains. The consequences have proved severe, for example, in Haiti, which has been completely deforested.

\section{Human Poverty Index (HPI)}

The Human Poverty Index indicates the standard of living in a country. Developed by the UN Development Programme (UNDP), it complements the Human Development Index (HDI). The Index's creators believe that in developed countries the Index reflects the level of deprivation and social exclusion better than HDI. Developing and developed countries are evaluated separately and using different indicators.

\section{HP Index for Developing Countries}

HP Index for developing countries is 'a composite index measuring deprivations in the three basic dimensions captured in the human development index - a long and healthy life, knowledge and a decent standard of living. The following indicators enter the calculation:

\footnotetext{
${ }^{10}$ Growth at the expense of ecological limits should be considered uneconomic.
} 
- $\quad$ probability at birth of not surviving to age 40 ;

- $\quad$ adult illiteracy rate;

- unweighted average of population without sustainable access to an improved water source and children under weight for age.

\section{HP Index for Selected OECD Countries}

HP Index for developed countries is 'a composite index measuring deprivations in the three basic dimensions captured in the human development index - a long and healthy life, knowledge, a decent standard of living - and also capturing social exclusion'. The following indicators enter the calculation:

- $\quad$ probability at birth of not surviving to age 60;

- adults lacking functional literacy skills;

- population below income poverty line;

- $\quad$ rate of long-term unemployment.

\section{State of the Future Index (SOFI)}

The State of the Future Index is a statistical combination of the values of 28 key indicators of the state of society, illustrating whether its situation will improve or deteriorate in the future (Gordon in: Glenn et al., 2011). SOFI is based on evaluation (by means of repeated questionnaires) carried out by selected experts who identify issues and trends conditioning future development (with a 10-year outlook). In questionnaires, experts assess the weight of the indicators and also of events that have not happened yet but, if they did, they would have a great (positive or negative) impact on society's development.

Based on the available data, SOFI has been assessed 20 years in retrospect, which allows the credible devising of future trends for roughly the next 10 years. In the past twenty years the overall SOFI has been improving but in the decade to come this positive trend is likely to slow down.

It is necessary to bear in mind that by creating one aggregated index, the perception of development within individual indicators is lost. Even with the overall index improving, one of the indicators may record a significant deterioration (e.g. an increase in terrorist attacks).

The 28 evaluated indicators can be classified into four groups based on how their values have developed in the past 20 years and how they are likely to develop in the next decade.

- Indicators that have improved in the past 20 years and are likely to continue to do so (even if at a slower rate) despite the ongoing economic recession: adult literacy rate; percentage of secondary school enrollment; countries having or thought to have plans for nuclear weapons; GDP per unit of energy use; number of major armed conflicts; population growth; number of physicians; number of Internet users; life expectancy at birth; number of women in parliaments.

- Indicators that have improved in the past 20 years but the trend may change due to the economic recession: access to drinking water; percentage of absolute poverty headcount; research and development expenditure; clean energy availability; food availability; per- 
centage of population in countries that are free; GDP per capita; number of refugees.

- Indicators that have deteriorated in the past 20 years but could improve in the next 10 years:percentage of people voting in elections; percentage of forest lands; prevalence of HIV (age category 15-49 years old).

- Indicators that have deteriorated in the past 20 years and the trend is likely to continue in the next 10 years:levels of corruption; $\mathrm{CO}_{2}$ emissions; unemployment rate; people killed or injured in terrorist attacks; global surface temperature anomalies; total debt service (debt burden).

\section{Quality and Sustainability of Life Index (SD Index)}

Between 1999 and 2004, Czech and Slovak methodology of creating and verifying indicators of sustainable development and quality of life was devised. The findings were published in several periodicals and books (Glenn, Gordon, 2001; Potůček et al., 2002, 2003; Mederly et al., 2002, 2003, 2004). The research was conducted under the auspices of the Millennium Project and was part of the research tasks of the Center for Social and Economic Strategies, Faculty of Social Sciences, Charles University in Prague.

The main objective was to illustrate quality and sustainability of life at each of the hierarchical levels with one aggregated indicator - index. The calculation followed an a priori approach (pre-determined internal structure of the index), using the methods of descriptive statistics (average-based aggregation).

We obtained all the original (primary) data from publicly accessible sources: the database World Development Indicators (World Bank), the Human Development Report (UNDP) and the data acquired from the NGO Freedom House.

When creating the 'Quality and Sustainability of Life Index', our main motivation was the challenge to find an overall index precisely capturing the progress of countries towards sustainable development based on generally available data for a sufficient number of countries. This would enable the regular comparison of the advance the countries make over a longer time span.

The findings enable comparison of individual countries in seven assessed areas of sustainable development:

1. Human rights, freedom, and equality.

2. Demographic indicators and life expectancy.

3. Health and health care.

4. Education, information technologies.

5. Economic development and foreign debt.

6. Resource consumption, ecological efficiency.

7. Environmental quality.

The overall index for individual countries was calculated as an arithmetical average of the transformed values of 64 variables. The Index was calculated for 179 countries; the overall data coverage was very good ( $91.2 \%$ of the required data was gathered). Over $50 \%$ of the data was available for all listed countries - the least for Afghanistan, St Thomas Island, the Democratic People's Republic of Korea, and Somalia, with less than $60 \%$ of variables available. 
The resulting values of the SD Index confirm the present division of the world and its polarisation into wealthy and developed countries in the North (very often at the cost of natural resource consumption) and poor, less developed countries in the South. The first category definitely includes the Western European countries, the USA, Canada, Australia, New Zealand, and Japan. The other group consists of the majority of African countries, some countries of Southern and Southeastern Asia, and Haiti from the Western hemisphere.

\section{Discussion}

Although the concept of sustainable development has been evolving for a quarter of century, it is still extremely vague, which stems from the effort to capture and respond to highly complex global (not only environmental) problems. Ján Topercer (Mederly et al., 2004) characterised the key weak point of the concept of sustainable development as follows:

- the idea of a universal hierarchy of needs has not been sufficiently empirically documented (Smelser, 1994), which applies to space (geographically) but perhaps even more to time;

- $\quad$ in addition, our standards of what is optimal and desirable develop over time;

- it is difficult to realise today's needs and capacities and their satisfaction, let alone the future ones, largely due to the fact that certain premises and facts are extremely vague;

- it is extremely difficult, even disputable, to realise and quantify a whole range of marginal conditions, variables, and their threshold values under which the ecosystem's sustainable development may turn unsustainable;

- it is difficult to conceptualise sustainable development, let alone design verifiable hypotheses and upon them develop a theory of sustainable development, which in this respect basically still does not exist.

While devising the quality and sustainability of life index, research teams are repeatedly confronted with issues for which there is no easy answer but which exercise a substantial influence over the quality and informative capacity of the constructed indexes:

- What is the informational value of two basic types of data - 'hard' (from statistical surveys) and 'soft' (from opinion polls)?

- $\quad$ Should indicators be given different weight?

- How can the optimum value of an indicator be defined?(For example, with literacy this is obvious - the higher the literacy, the better.The situation is less clear with the daily calorie intake per person or with military expenditure).

- Should we aim at creating an optimal set of indicators (some of which have not been monitored yet) or be practical and select indicators for which there is a monitoring history and a longer time series available?

These and other questions have a considerable impact on the quality of the resulting indexes.

\section{Conclusion}

Sustainable development anticipates development that would not compromise the ability of future generations to meet their needs as viewed from the perspective of today's generation. This concept of development is considered desirable, which makes it assume a prescribing 
rather than predicting role (Topercer in: Mederly et al., 2004). Although the concept of sustainable development is far from flawless and is not a scientific theory, there is no better way (so far) to attempt to respond to the ever more acute problems of global scale.

What we observed at the beginning of this article remains valid - we urgently need a generally accepted and respected alternative index (or indexes) to GDP. Even though GDP is good for measuring economic performance, it is highly misleading as an indicator of the quality and sustainability of life. The most promising alternatives today seems to be Human Development Index (HDI), Ecological Footprint and also State of the Future Index (SOFI), which is designed to create a systematic and rational answer whether the outlook for the future is likely to improve towards sustainable way of life or not.

\section{References}

Daly, H.E. \& Cobb B.J. (1989). For the common good. Redirecting the economy toward community, the environment, and a sustainable future. Boston: Beacon Press.

Daly, H.E. (1996). Beyond growth. Boston: Beacon Press.

Esty, D.C., Levy, M.A., Kim, C.H., de Sherbinin, A., Srebotnjak, T. \& Mara V. (2008). 2008 Environmental performance index. New Haven: Yale Center for Environmental Law and Policy.

Glenn, J.C. \& Gordon T.J. (2001). State of the future. Washington: The Millennium Project.

Glenn, J.C., Gordon, T.J. \& Florescu E. (2011). State of the future. Washington: The Millennium Project.

Human Rights Watch (2003): World report 2003. New York: Human Rights Watch.

Jackson, T., Marks, N., Ralls, J. \& Strymme S. (1997). An index of sustainable economic welfare for the UK 1950-1996. Guildford: Centre for Environmental Strategy, University of Surrey.

Meadows, D.H., Meadows, D.L. \& Randers J. (1972). The limits to growth. New York: Universe Books.

Meadows, D.H., Meadows, D.L. \& Randers J. (1992). Beyond the limits. Vermont: Chelsea Green Publishing Co.

Mederly, P. (Ed.) (2001). Sustainable development - challenge for Slovakia (in Slovak). Bratislava: MŽP SR.

Mederly, P., Nováček, P. \& Topercer J. (2002). How to measure progress towards sustainability - the sustainable development index. Futures Research Quarterly, 18(2), 5-24.

Mederly, P., Nováček, P. \& Topercer J. (2003). Sustainable development assessment: quality and sustainability of life indicators at global, national and regional level. Foresight, 5(5), 42-49. DOI: 10.1108/14636680310507307.

Mederly, P., Topercer, J. \& Nováček P. (2004). Quality and sustainability of life indicators. Quantitative, multidimensional and variant approach (in Czech). Praha: UK FSV CESES.

Mederly, P. (2006). Indicators of sustainable development (in Slovak). Nitra: FPV UKF.

Nováček, P. (2011). Sustainable development. Olomouc: Univerzita Palackého.

Potůček, M. et al. (2002). Guide to the priorities for the Czech Republic (in Czech). Praha: Univerzita Karlova. http//:vize-cr. fsv.cuni.cz

Potůček, M. et al. (2003). Human development report Czech Republic (in Czech). Praha: Univerzita Karlova.

Rees, W. (1992). Ecological footprints and appropriated carrying capacity: what urban economics leaves out. Environment and Urbanization, 4(2), 121-130. DOI: 10.1177/095624789200400212.

Smelser, N.J. (1994). Sociology. Cambridge: Blackwell.

Topercer, J. (1996). Sustainable development - outline of theoretical framework (in Slovak). In Nováček, P., Mederly, P. a kol. (Eds.), Strategie udržitelného rozvoje. Praha: G plus G.

Transparency International (2009). Corruption perceptions index. Berlin: Transparency International.

United Nations Development Programme (2008/2009). Human development report. New York: Palgrave Macmillan.

United Nations World Commission on Environment and Development (1987). Our common future. Oxford: Oxford University Press.

World Bank (2003). World development indicators. Washington, D.C.: World Bank.

World Resource Institute (2005). Millennium ecosystem assessment: ecosystems and human well-being. Synthesis. Washington, D.C.: Island Press.

World Watch Institute (2009). State of the world. Into a warming world. New York, London: W.W. Norton and Company. World Wide Fund for Nature (2008). Living planet report. Gland: WWF. 